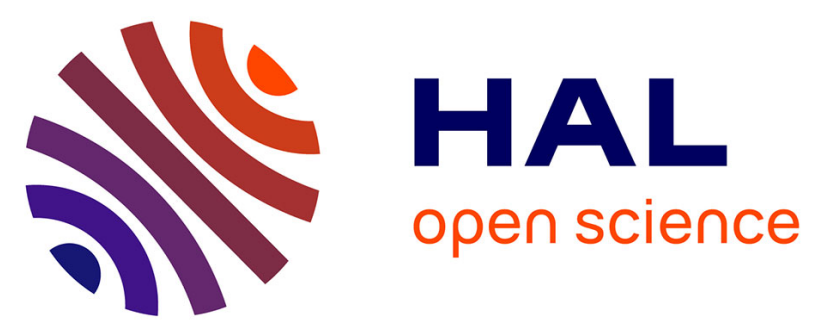

\title{
Identification of Model Parameter for the Simulation of SMA Structures Using Full Field Measurements
}

Yves Chemisky, Fodil Meraghni, Nadine Bourgeois, Stephen Cornell, Rachid Echchorfi, Etienne Patoor

\section{- To cite this version:}

Yves Chemisky, Fodil Meraghni, Nadine Bourgeois, Stephen Cornell, Rachid Echchorfi, et al.. Identification of Model Parameter for the Simulation of SMA Structures Using Full Field Measurements. TMS Middle East - Mediterranean Materials Congress on Energy and Infrastructure Systems (MEMA 2015), Jan 2015, Doha, Qatar. 10.1002/9781119090427.ch19 . hal-02521484

\section{HAL Id: hal-02521484 \\ https://hal.science/hal-02521484}

Submitted on 27 Mar 2020

HAL is a multi-disciplinary open access archive for the deposit and dissemination of scientific research documents, whether they are published or not. The documents may come from teaching and research institutions in France or abroad, or from public or private research centers.
L'archive ouverte pluridisciplinaire HAL, est destinée au dépôt et à la diffusion de documents scientifiques de niveau recherche, publiés ou non, émanant des établissements d'enseignement et de recherche français ou étrangers, des laboratoires publics ou privés. 


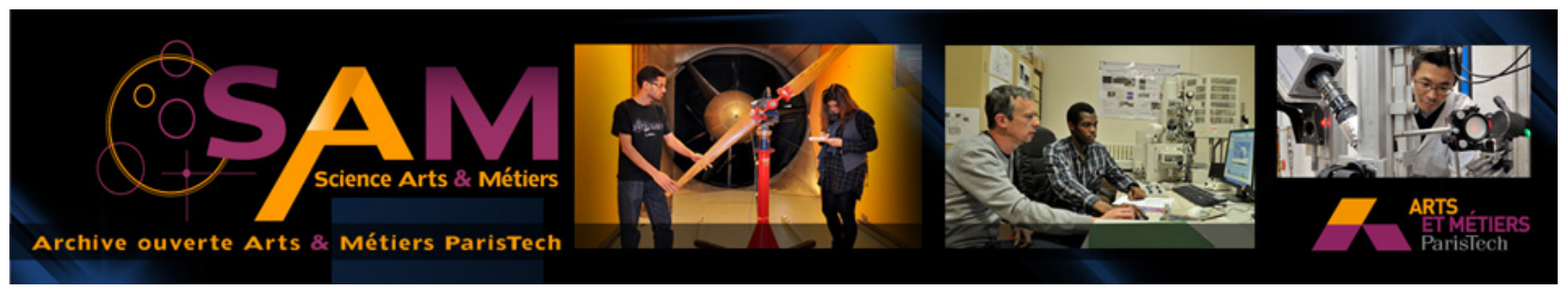

Science Arts \& Métiers (SAM)

is an open access repository that collects the work of Arts et Métiers ParisTech researchers and makes it freely available over the web where possible.

This is an author-deposited version published in: http://sam.ensam.eu Handle ID: .http://hdl.handle.net/null

\section{To cite this version :}

Yves CHEMISKY, Fodil MERAGHNI, Nadine BOURGEOIS, Stephen CORNELL, Rachid ECHCHORFI, Etienne PATOOR - Identification of Model Parameter for the Simulation of SMA Structures Using Full Field Measurements - 2015 


\title{
Identification of Model Parameter for the Simulation of SMA Structures Using Full Field Measurements
}

\author{
Yves Chemisky $^{1}$, Fodil Meraghni ${ }^{1}$, Nadine Bourgeois ${ }^{2}$, Stephen Cornell ${ }^{3}$, Rachid \\ Echchorfi $^{1}$, Etienne Patoor ${ }^{1}$ \\ ${ }^{1}$ Arts et Métiers ParisTech Metz, LEM3 UMR CNRS 7239, Metz, France \\ ${ }^{2}$ Université de Lorraine, LEM3 UMR CNRS 7239, Metz, France \\ ${ }^{3}$ Dept. of Aerospace Engineering, Texas A\&M University
}

Keywords: Identification, optimization, Shape Memory Alloys, heterogeneous tests

\begin{abstract}
With the design of new devices with complex geometry and to take advantage of their large recoverable strains, shape memory alloys components (SMA) are increasingly subjected to multiaxial loadings. The development process of SMA devices requires the prediction of their thermomechanical response, where the calibration of the material parameters for the numerical model is an important step. In this work, the parameters of a phenomenological model are extracted from multiaxial and heterogeneous tests carried out on specimens with the same thermomechanical loading history. Finite element analysis enables the computation of numerical strain fields using a thermodynamical constitutive model for shape memory alloys previously implemented in a finite element code. The strain fields computed numerically are compared with experimental ones obtained by DIC to find the model parameters which best matches experimental measurements using a newly developed parallelized mixed genetic/gradient-based optimization algorithm. These numerical simulations are carried out in parallel in a supercomputer to reduce the time necessary to identify the set of identified parameters. The major features of this new algorithm is its ability to identify material parameters of the thermomechanical behavior of shape memory alloys from full-field measurements for various loading conditions (different temperatures, multiaxial behavior, heterogeneous test configurations). It is demonstrated that model parameters for the simulation of SMA structures are thus obtained based on a reduced number of heterogeneous tests at different temperatures.
\end{abstract}

\section{Introduction}

Shape memory Alloys Metals (SMA) are utilized in a wide range of applications and incorporated in more and more complex systems. Their unique ability to recover substantial deformation when subjected to particular thermomechanical load made them very attractive and suitable for actuator devices and to replace complex assemblies. The development of new design solution, combining three-dimensional models along with an integration in Finite Element Analysis (FEA) packages, has contributed to the appearance of Shape Memory Alloys parts with complex geometrical shape. It has been recently noticed that the development of modern computer design and analysis tools based on three-dimensional constitutive models, calibrated from carefully obtained material characterisation and experimental data is considered essential for the development process of SMA applications (Mohd Jani et al., 2014) 
These structures are subjected to heterogeneous loading conditions, where the material locally undergoes non-proportional loadings. Once provided with the adequate material parameters, the three-dimensional constitutive models based on thermodynamics of irreversible processes can predict accurately and efficiently the behavior of such multiaxial, non-proportional loading. A review of these models for SMAs can be found in Patoor et al. (2006) for the behavior of the single crystal and Lagoudas et al. (2006) for the constitutive modeling of polycrystals. The design of SMA structures and the optimization of their characteristics relies now on finite element analysis, which constitutes a powerful tool, especially for components subjected to complex loading. The accuracy of numerical simulations of the SMA structural behavior relies on the model ability to accurately account for uniaxial but also multiaxial, non-proportional loadings. However, these solutions require more advanced characterization techniques than the uniaxial tension or thermal analysis recommended by the ASTM standards (F2004, 2005; F2082, 2003). For homogeneous tests, a recent method has been developed to identify the phase transformation parameters from a set of experiments, utilizing a gradient-based inverse approach (Meraghni et al., 2014). A similar approach has been adopted to determine the parameter of a SMA model from experimental data (Whitten and Hartl, 2014).

However, even if identification strategies based on optimization algorithms have been used, these methods require the experimental characterization of specimen of several natures (tensile dogbone specimen, double shear specimens, thin tubes) to obtain the whole set of material parameters required for Finite Element (FE) simulations. In the case of $\mathrm{Ni}$-Ti shape Memory Alloys, the processing of these specimens strongly influences the behavior (Ren and Otsuka, 2005) and thus the extraction of a unique set of parameters that represents the material behavior is not possible. Moreover, localization effects may be observed in specimens of simple geometry subjected to homogeneous loading, but the SMA device will not necessarily exhibit such effects, depending on its geometry and loading conditions. The identification of material parameters on specimens as close as possible to the final product shall be preferred for these reasons. Moreover, the design process is accelerated if the characterization requires only a few specimens. The identification procedure that utilizes full-field kinematical fields seems thus to be an appropriate method for the identification of the set of material parameters for the purpose of SMA devices design, that may include parameters characteristic of loading-path dependent behavior.

Identification methods coupled with kinematical fields measurement have been extensively developed in the last decades. The most used methods are described in the useful review work of Avril et al. (2008), where the advantages and drawbacks of each method is described extensively. The FEMU approach, proposed by Kavanagh and Clough (1971) is the most intuitive, and has a lot of flexibility with regard to the definition of the cost function. Furthermore, the FEMU approach has the advantage to perform at the same time a parametric study of the material parameters, utilizing the numerical simulations performed for the identification, assuming that the design space has been sufficiently explored.

Following these considerations, in this work a FEMU method is developed and coupled with an innovative combined genetic/gradient-based optimization algorithm. Since Finite Element Analyses are necessary to compare the experimental data with the numer- 
ical simulations, a specific attention is devoted to the parallelization of such approach in a supercomputer. Based on all the previously discussed points, the proposed work focuses on the development of a parallelized hybrid identification procedure for the parameters of the model of Lagoudas et al. (2012) that has the following features:

1. It is adapted to the identification of material parameters directly on an SMA structure under very different solicitation (i.e. local thermomechanical paths)

2. It is based on the definition of a cost function by means of a square difference of the experimental and numerically computed variables (strains and forces).

3. A parallelized optimization algorithm is utilized, which combine an evolutionary algorithm with the Levenberg-Marquardt algorithm

\section{Material selection and experimental procedure}

The material utilized for the experiments was a NiTi (Ti50.4Ni) shape memory alloy. It has been received in a fully annealed state and provided by Nimesis Technology in the form of plates (2.5 mm thickness). Samples were cut using waterjet hyperbaric machining and annealed $\left(400^{\circ} \mathrm{C}, 30 \mathrm{~min}\right)$ followed by a water-quenching. The mechanical test is a non-standard tensile test inspired from the work by Meuwissen et al. (1998). This nonstandard test configuration gives rise to heterogeneous and non-uniform in-plane strain fields, namely longitudinal (in the direction of loading), transverse and shear strain components. By using such a heterogeneous specimen, the behavior of shear strain and stress may be demonstrated in conjunction with the principal strain and stress on the same specimen. While the sample geometry is complex, it is loaded using an uniaxial tensile test machine. The specimen is loaded under applied displacement, into a thermal chamber with a crosshead velocity of $0.5 \mathrm{~mm} /$ minute. This value has been set from previous experiments to obtain a maximal quasi-static strain rate of the range of $10^{-3} \mathrm{~s}^{-1}$ even in the area where the strains are localized, i.e. between the notches. By incrementing the applied traction, one obtains hence a spatio-temporal distribution of the strain, which are measured using optical whole-field displacement/strain measurements by digital image correlation (DIC).Three experiments were performed at different temperatures : 50 ${ }^{\circ} \mathrm{C}, 60{ }^{\circ} \mathrm{C}$ and $70{ }^{\circ} \mathrm{C}$, respectively.

\section{Thermomechanical model of martensitic transformation for SMAs and model parameters}

The model proposed by Lagoudas et al. (2012) describes the behavior of a Shape Memory Alloy representative volume element (RVE). This model has been implemented in the FEA package Abaqus, which is used in this work to perform the finite element simulations. The model parameters of this model can be deducted from a unified set of material parameters has been defined by Stebner et al. (2011) (see Table 1).

Considering that the SMA is subjected only to superelastic loadings, it is unnecessary to identify the two parameters associated with martensitic reorientation $\sigma^{s}$ and $\sigma^{f}$. Moreover, since it is assumed that the transformation hardening is proportional to the 
Table 1: Material parameters for typical NiTi materials

\begin{tabular}{cr}
\hline$E^{A}\left(E^{M}\right)(\mathrm{MPa})$ & Elastic Modulus, Austenite (Martensite) \\
$\nu^{A}\left(\nu^{M}\right)$ & Poisson ratio of Austenite (Martensite) \\
$\alpha^{A}\left(\alpha^{M}\right)$ & Coeff. Thermal Exp., Austenite (Martensite) \\
$M_{s}$ & Mart. Start Temperature, $\sigma=0$ \\
$M_{f}$ & Aust. Finish Temperature, $\sigma=0$ \\
$A_{s}$ & Mart. Start Temperature, $\sigma=0$ \\
$A_{f}$ & Aust. Finish Temperature, $\sigma=0$ \\
$C^{M}$ & Uniaxial stress - temperature slope, forward transformation \\
$C^{A}$ & Uniaxial stress - temperature slope, reverse transformation \\
$\sigma^{s}$ & Martensitic reorientation start \\
$\sigma^{f}$ & Martensitic reorientation finish \\
$\varepsilon^{a c t m a x}$ & Maximum recoverable transformation strain \\
\hline
\end{tabular}

volume fraction of martensite, a relationship is assumed between $M_{f}-M_{s}, C^{M}$ and $A_{f}-A_{s}, C^{A}$. An additional parameter is introduced to represent such relation, already utilized by Peultier et al. (2006) and Chemisky et al. (2011) has been defined:

$$
H_{f}=\varepsilon^{a c t \max } * C^{M} *\left(M_{f}-M_{s}\right)=\varepsilon^{a c t m a x} * C^{A} *\left(A_{f}-A_{s}\right),
$$

such that the knowledge of $\varepsilon^{a c t m a x}, C^{M}, C^{A}, M_{s}, A_{f}$ and $H_{f}$ is sufficient for the knowledge of the martensitic transformation characteristics. Furthermore, the effect of thermal expansion is neglected for superelastic loadings and the elastic parameters are assumed to be the same for the austenitic and martensitic phases. With such conditions, The remaining eight independent parameters are $E(\mathrm{MPa}), \nu, H_{f}(\mathrm{MPa}), \varepsilon^{a c t m a x}$, $C_{M}\left(\mathrm{MPa} .{ }^{\circ} \mathrm{C}^{-1}\right), C_{A}\left(\mathrm{MPa} .{ }^{\circ} \mathrm{C}^{-1}\right), M_{s}\left({ }^{\circ} \mathrm{C}\right)$ and $A_{f}\left({ }^{\circ} \mathrm{C}\right)$.

\section{Parameter identification using Finite Element updating method coupled with an hybrid optimization algorithm}

Having a constitutive model with a specific set of material parameters, the identification problem consists of the determination of material parameters that minimize the difference between computed data and a set of experimental data. The cost function is considered to be:

$$
C(\mathbf{p})=\frac{1}{2} \sum_{i} \frac{1}{N_{i}}\left(v_{i}^{n u m}(\mathbf{p})-v_{i}^{e x p}\right)
$$

where $C(\mathbf{p})$ is the cost function, $v_{i}^{\text {num }}(\mathbf{p})$ is the i-th information obtained with the numerical simulation, $v_{i}^{e x p}$ is the i-th information obtained from the set of experiments conducted and $N_{i}$ is a weight factor. Note that all these informations are potentially obtained from a number of experiments at different times and at different spatial positions.

In the methodology proposed here, the boundary conditions are determined using the displacement experimentally measured using DIC at the lower and upper boundary (as 
$y$ is considered as the vertical axis) of the zone of interest. Considering a thin specimen, on the left and right side and on the front and back faces it is assumed that no tractions are applied to complete the definition of the boundary-value problem. The experimental data utilized for the definition of the cost function are (i) the in-plane strain field (derived from the displacement field obtained by DIC) and (ii) the information of forces measured by means of the load cell in the experimental setup. To minimise the cost function and obtain appropriate model parameters, genetic algorithm and gradient-based method are used simultaneously, with the following procedure:

1. An initial population of $C_{0}$ individuals (each individual is a set of parameters) is generated. The selection of individuals can be aleatory, given limitations of the material parameters, or can be generated using Design Of Experiments (DOE).

2. The numerical simulation for all the individual is computed in parallel. The cost function of all the individual is thus determined

3. A set of children of the current generation (with $n$ members) are determined using the crossover technique from a set of the best individuals. A mutation probability has been added to increase the diversity of the children generation.

4. The bests members of the current generation are selected and a gradient-based method (Levenberg-Marquardt) is utilized to find an update of their parameters.

5. The current generation $n+1$ is determined from the the best individuals among the current generation $n$ and the children

6. Stationary condition test for the best individual of the current generation compared to the previous best. If needed, reloop from item 5

On overview of the identification procedure in general is presented in Figure 1

A finite element model has been developed using Abaqus. Only an area close to the notches is considered for the model that corresponds to the window recorded by the camera. Over a full loading-unlading cycle, the values of the strain of the material points are compared on 20 increments, uniformly spaced according to the applied displacement.

\section{Parameter identification results and validation of the identification procedure}

The developed identification software has been ran on a cluster to be able to parallelize the numerical simulations. This is achieved using a software dedicated to the generation of jobs coupled with TORQUE Resource Manager for the management of the execution of those jobs on the cluster. The set of initial parameters is bounded to define the design space (see Tab. 2):

The final material parameters have been identified and presented in Table 3 . It is noted that a sufficient initial population is necessary to be able to efficiently find a good starting point close enough to the global minima for the gradient-based algorithm. Indeed, according to the complexity of the behavior, the number of experimental points 


\section{Identification strategy}

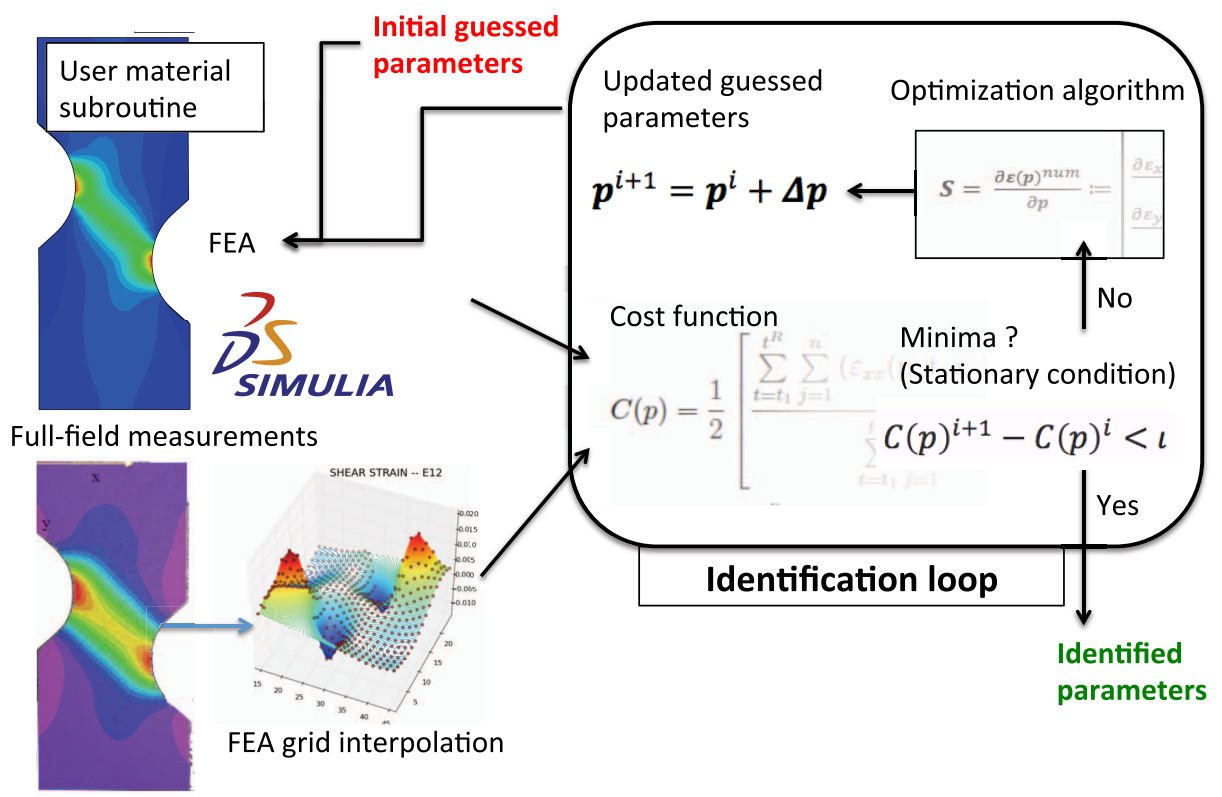

Figure 1: Overview of the identification procedure

Table 2: Min and max bounds for the material parameters

\begin{tabular}{ccccc}
\hline & $E(\mathrm{MPa})$ & $\nu$ & $H_{f}(\mathrm{MPa})$ & $\varepsilon_{\text {trac }}^{T}$ \\
$\min$ & 50000 & 0.2 & 0.5 & 0.03 \\
$\max$ & 80000 & 0.45 & 6 & 0.05 \\
\hline & $\left.C^{M}\left(\mathrm{MPa} \cdot{ }^{\circ} \mathrm{C}^{-1}\right)\right)$ & $C^{A}\left(\mathrm{MPa}^{\circ} \mathrm{C}^{-1}\right)$ & $M_{S}\left({ }^{\circ} \mathrm{C}\right)$ & $A_{f}\left({ }^{\circ} \mathrm{C}\right)$ \\
$\min$ & 4 & 4 & -73 & -33 \\
$\max$ & 12 & 12 & 27 & 47 \\
\hline
\end{tabular}

and the noise introduced by the experimental measurement of DIC, local minima close to the global minimum solution are expected.

The comparison between the strain field obtain using DIC and the numerical simulation with the identified parameters is shown in Figure 2. Globally, the correlation between the experimental and simulated fields are very close, especially in the area where the strain are rather large due to the localization effect induced by the presence of notches. It is further noticed that differences appear for the longitudinal strain $\varepsilon_{y y}$ and the in-plane shear strain $\varepsilon_{x y}$ around the notches.

The overall mechanical response of the sample, in terms of the evolution of force with respect to the average displacement at the boundary of the DIC window is compared in Figure 3. It is shown that globally the overall behaviour during loading is accurately represented by the numerical model using the identified parameters. The behaviour during unloading is correctly simulated for the test performed at $50^{\circ} \mathrm{C}$. More pronounced 

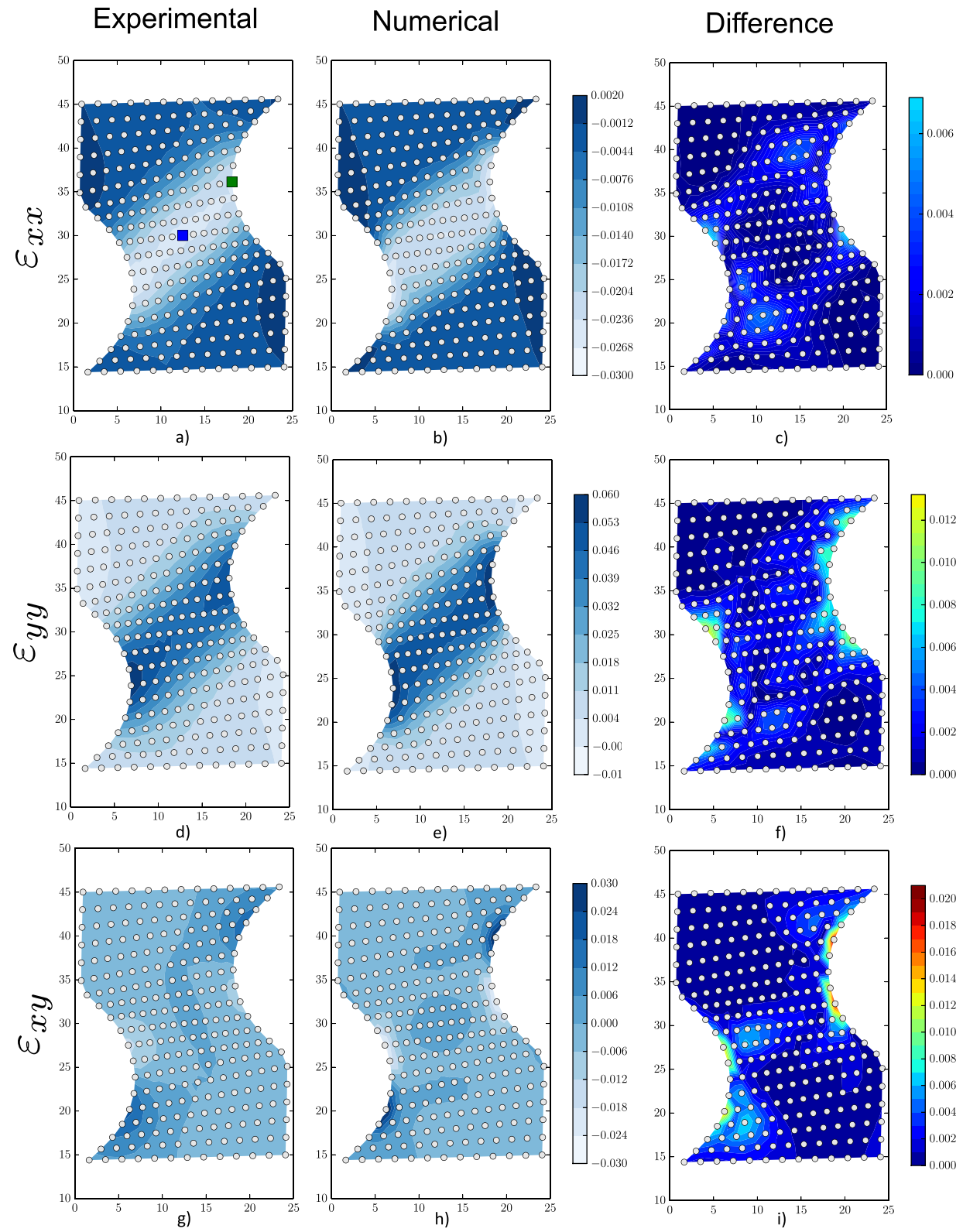

Figure 2: Contour plots of the experimental strain fields (a,d, g), the numerical strain fields $(\mathrm{b}, \mathrm{e}, \mathrm{h})$ and their absolute difference $(\mathrm{c}, \mathrm{f}, \mathrm{i})$ for the components $\varepsilon_{x x}, \varepsilon_{y y}$ and $\varepsilon_{x y}$, respectively 
Table 3: Identified material parameters NiTi materials

\begin{tabular}{cccc}
\hline$E(\mathrm{MPa})$ & $\nu$ & $H_{f}(\mathrm{MPa})$ & $\varepsilon_{\text {trac }}^{T}$ \\
67500 & 0.394 & 1.79 & 0.0416 \\
\hline$\left.C^{M}\left(\mathrm{MPa} .{ }^{\circ} \mathrm{C}^{-1}\right)\right)$ & $C^{A}\left(\mathrm{MPa}^{\circ} \mathrm{C}^{-1}\right)$ & $M_{S}\left({ }^{\circ} \mathrm{C}\right)$ & $A_{f}\left({ }^{\circ} \mathrm{C}\right)$ \\
8.74 & 9.66 & -14.5 & 5.5 \\
\hline
\end{tabular}

differences appear during reverse transformation, especially at $60^{\circ} \mathrm{C}$ and $70^{\circ} \mathrm{C}$. It is noted here that the transformation hardening characteristics have been selected to be similar between forward and reverse transformation. The selection of different hardening parameters could have improved the results, with the cost of increasing the number of parameters to identify.

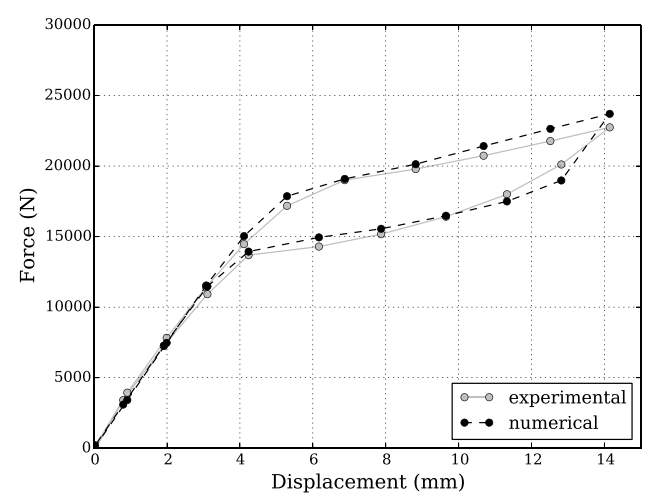

a)

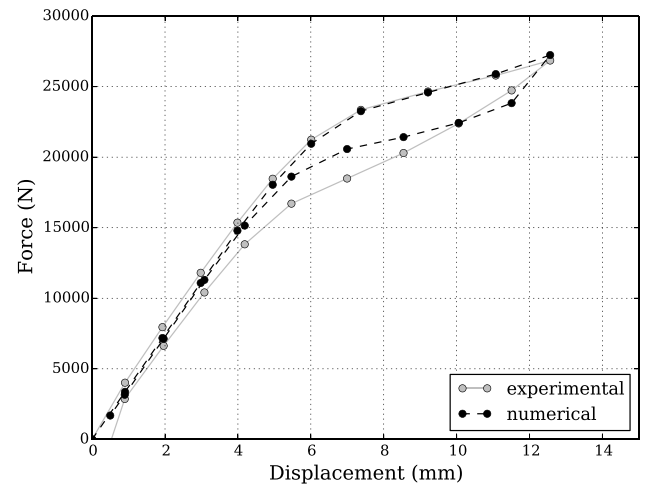

c)

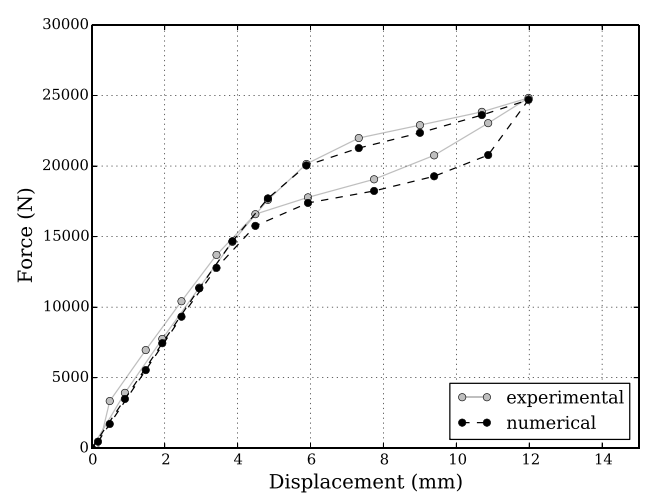

b)

Figure 3: Comparison between the force vs displacement response obtain from experimental characterisation and numerical simulation with the identified material parameters 


\section{Conclusions}

In this work, an inverse identification procedure has been developed to determine the material parameters of SMAs directly on structures using full field measurements. The proposed identification method, using a parallelized hybrid genetic-gradient based optimisation algorithm, is able to properly identify the material parameters of a Shape Memory Alloy. It has been noted that a large initial population is important to be able to rapidly select a good starting point for a gradient-based Levenberg-Marquardt algorithm, avoiding hence local minima. Such an identification method is of great importance for material that are extremely sensitive to thermomechanical processing conditions, e.g. NiTi materials where it is very difficult to test the material properties since processing conditions of the device could not be easily reproduced on the simple test samples. Thus, it is very difficult to proceed in such cases with the legacy calibration methods and identification procedures have to utilize the thermomechanical characterization of the structures, often implying heterogeneous conditions. Furthermore, exploiting the heterogeneity of the local strain paths, this method can also be utilized to extract material parameters that are difficult to obtain based on uniaxial experiments, such as material parameters characteristic of anisotropy and tension-compression asymmetry, since this method applies to heterogeneous tests with local multiaxial non-proportional conditions.

\section{Acknowledgment}

The support of the NSF International Institute of Multifunctional Materials for Energy Conversion (IIMEC), award \#0841082, is acknowledged.

\section{References}

Avril, S., Bonnet, M., Bretelle, A., Grediac, M., Hild, F., Ienny, P., Latourte, F., Lemosse, D., Pagano, S., Pagnacco, E., Pierron, F., 2008. Overview of identification methods of mechanical parameters based on full-field measurements. Experimental Mechanics 48, 381-402.

Chemisky, Y., Duval, A., Patoor, E., Zineb, T. B., 2011. Constitutive model for shape memory alloys including phase transformation, martensitic reorientation and twins accommodation. Mechanics of Materials 43 (7), 361-376.

F2004, A., 2005. Standard Test Method for Transformation Temperature of NickelTitanium Alloys by Thermal Analysis. ASTM International.

F2082, A., 2003. Standard Test Method for Determination of Transformation Temperature of Nickel-Titanium Shape Memory Alloys by Bend and Free Recovery. ASTM International.

Kavanagh, K., Clough, R., 1971. Finite element applications in the characterization of elastic solids. International Journal of Solids and Structures 7, 11-23. 
Lagoudas, D., Hartl, D., Chemisky, Y., Machado, L., Popov, P., 2012. Constitutive model for the numerical analysis of phase transformation in polycrystalline shape memory alloys. International Journal of Plasticity 32-33, 155-183.

Lagoudas, D. C., Entchev, P. B., Popov, P., Patoor, E., Brinson, L. C., Gao, X., 2006. Shape memory alloys, Part II: Modeling of polycrystals. Mechanics of Materials 38 (56), 430-462.

Meraghni, F., Chemisky, Y., Piotrowski, B., Echchorfi, R., Bourgeois, N., Patoor, E., 2014. Parameter identification of a thermodynamic model for superelastic shape memory alloys using analytical calculation of the sensitivity matrix. European Journal of Mechanics - A/Solids 45, 226-237.

Meuwissen, M., Oomens, C., Baaijens, F., Petterson, R., Janssen, J., 1998. Determination of the elasto-plastic properties of aluminium using a mixed numericalexperimental method. Journal of Materials Processing Technology 75 (1), 204-211.

Mohd Jani, J., Leary, M., Subic, A., Gibson, M., 2014. A review of shape memory alloy research, applications and opportunities. Materials and Design 56, 1078-1113.

Patoor, E., Lagoudas, D. C., Entchev, P. B., Brinson, L. C., Gao, X., 2006. Shape memory alloys, Part I: General properties and modeling of single crystals. Mechanics of Materials 38 (5-6), 391-429.

Peultier, B., Ben Zineb, T., Patoor, E., 2006. Macroscopic constitutive law of shape memory alloy thermomechanical behaviour. Application to structure computation by FEM. Mechanics of Materials 38, 510-524.

Ren, X., Otsuka, K., 2005. Physical metallurgy of ti-ni-based shape memory alloys. Progress in Material Sciences 50, 511-678.

Stebner, A., Hartl, D., Chemisky, Y., Benefan, O., Turner, T., Calkins, F., Padula, S., Seelecke, S., Brinson, L., Lagoudas, D., 2011. Development of frameworks for comparing shape memory alloy models: 3d phenomenological continuum models. In: SMASIS Smart Materials, Adaptive Structures and Intelligent Systems. ASME.

Whitten, W., Hartl, D., 2014. Iterative calibration of a shape memory alloy constitutive model from $1 \mathrm{~d}$ and $2 \mathrm{~d}$ experimental data using optimization methods. In: SPIE Smart Structures and Materials+ Nondestructive Evaluation and Health Monitoring. International Society for Optics and Photonics, pp. 905804-905804. 